\title{
Numerical Scheme for Solving Singular Two-Point Boundary Value Problems
}

\author{
N. Ratib Anakira, ${ }^{1}$ A. K. Alomari, ${ }^{2}$ and I. Hashim ${ }^{1}$ \\ ${ }^{1}$ School of Mathematical Sciences, Universiti Kebangsaan Malaysia, 43600 Bangi, Selangor, Malaysia \\ ${ }^{2}$ Department of Mathematics, Faculty of Science, Hashemite University, 13115 Zarqa, Jordan
}

Correspondence should be addressed to N. Ratib Anakira; alanaghreh_nedal@yahoo.com

Received 25 December 2012; Revised 5 March 2013; Accepted 11 March 2013

Academic Editor: Saeid Abbasbandy

Copyright (C) 2013 N. Ratib Anakira et al. This is an open access article distributed under the Creative Commons Attribution License, which permits unrestricted use, distribution, and reproduction in any medium, provided the original work is properly cited.

\begin{abstract}
Singular two-point boundary value problems (BVPs) are investigated using a new technique, namely, optimal homotopy asymptotic method (OHAM). OHAM provides a convenient way of controlling the convergence region and it does not need to identify an auxiliary parameter. The effectiveness of the method is investigated by comparing the results obtained with the exact solution, which proves the reliability of the method.
\end{abstract}

\section{Introduction}

Consider singular two-point boundary value problems (BVPs) of the form

$$
\frac{1}{p} u^{\prime \prime}(x)+\frac{1}{q(x)} u^{\prime}(x)+\frac{1}{r(x)}=g(x), \quad 0 \leq t \leq 1,
$$

subject to the boundary conditions

$$
u(0)=\alpha_{1}, \quad u(1)=\beta, \quad \text { or } \quad u^{\prime}(0)=\alpha_{2}, \quad u(1)=\beta,
$$

where $p, q, r$, and $g$ are continuous functions on $(0,1]$ and the parameters $\alpha_{1}, \alpha_{2}$, and $\beta$ are real constants.

Problems of the forms (1) and (2) are encountered in the fields of fluid mechanics, reaction-diffusion processes, chemical kinetics, optimal control, and other branches of applied mathematics [1,2]. Many different numerical methods have been proposed by various authors regarding singular twopoint boundary value problems such as variational iteration method (VIM) [3], cubic splines [4], differential transformation method (DTM) [5], the Adomian decomposition method (ADM) [6], continuous genetic algorithm (CGA) [7], sinc-Galerkin method and homotopy perturbation method
(HPM) [8-13], and homotopy analysis method (HAM) [14-23]. The existence of a unique solution of (1) and (2) was discussed in $[24,25]$.

Recently, Marinca et al. introduced and developed optimal homotopy asymptotic method (OHAM) in a series of papers [26-29] for the approximate solutions of nonlinear problems. OHAM does not depend on the presence of a small parameter. An advantage of OHAM is that it does not need to identify the $\hbar$-curve as in HAM for convergence region. In OHAM, the control and adjustment of the convergence region is provided in a convenient way. Furthermore, it has a built-in convergence criteria similar to HAM but with a greater degree of flexibility.

In this paper, OHAM is presented to create an approximate analytic solution of singular two-point boundary value problems. The method is directly applied without any linearization and discretizations and without splitting the nonhomogeneous term. The structure of this paper is organized as follows: Section 2 is devoted to the analysis of the proposed method, in Section 3, three examples are employed to illustrate the accuracy and computational efficiency of this approach, and lastly, conclusions are given in the last section. 


\section{Analysis of the Method}

To illustrate the basic idea of OHAM [30], we consider the following differential equation:

$$
L(u(x))+g(x)+N(u(x))=0, \quad B\left(u, \frac{\mathrm{d} u}{\mathrm{~d} x}\right)=0,
$$

where $L$ is the chosen linear operator, $N$ is the linear or nonlinear operator, $u(x)$ is an unknown function, $x$ denotes an independent variable, $g(x)$ is a known function, and $B$ is a boundary operator.

According to the basic idea OHAM we construct a homotopy $h(v(x, p), p): R \times[0,1] \rightarrow R$ which satisfies

$$
\begin{gathered}
(1-p)\left[L(v(x, p))-u_{0}(x)\right] \\
=H(p)[L(v(x, p))+g(x)+N(v(x, p))], \\
B\left(v(x, p), \frac{\partial v(x, p)}{\partial x}\right)=0,
\end{gathered}
$$

where $x \in R$ and $p \in[0,1]$ is an embedding parameter, $H(p)$ is a nonzero auxiliary function for $p \neq 0, H(0)=0$, and $v(x, p)$ is an unknown function. Obviously, when $p=0$ and $p=1$ it holds that $v(x, 0)=u_{0}(x)$ and $v(x, 1)=u(x)$, respectively. Thus, as $p$ varies from 0 to 1 , the solution $v(x, p)$ approaches from $u_{0}(x)$ to $u(x)$ where $u_{0}(x)$ is the initial guess that satisfies the linear operator and the boundary conditions

$$
L\left(u_{0}(x)\right)=0, \quad B\left(u_{0}, \frac{\mathrm{d} u_{0}}{\mathrm{~d} x}\right)=0 .
$$

Next, we choose the auxiliary function $H(p)$ in the form

$$
H(p)=p C_{1}+p^{2} C_{2}+p^{3} C_{3}+\cdots,
$$

where $C_{1}, C_{2}, C_{3}, \ldots$ are constants which can be determined later. $H(p)$ can be expressed in many forms as reported by Marinca et al. [26-29].

To get an approximate solution, we expand $v\left(x, p, C_{i}\right)$ in Taylor's series about $p$ in the following manner:

$$
v\left(x, p, C_{i}\right)=u_{0}(x)+\sum_{k=1}^{\infty} u_{k}\left(x, C_{1}, C_{2}, \ldots, C_{k}\right) p^{k} .
$$

Substituting (7) into (4) and equating the coefficient of like powers of $p$, we obtain the following linear equations. The zeroth-order problem is given by (5); the first- and secondorder problems are given as

$$
\begin{gathered}
L\left(u_{1}(x)\right)+g(x)=C_{1} N_{0}\left(u_{0}(x)\right), \quad B\left(u_{1}, \frac{\mathrm{d} u_{1}}{\mathrm{~d} x}\right)=0 \\
L\left(u_{2}(x)\right)-L\left(u_{1}(x)\right) \\
=C_{2} N_{0}\left(u_{0}(x)\right) \\
+C_{1}\left[L\left(u_{1}(x)+N_{1}\left(u_{0}(x), u_{1}(x)\right)\right],\right. \\
B\left(u_{2}, \frac{\mathrm{d} u_{2}}{\mathrm{~d} x}\right)=0 .
\end{gathered}
$$

The general governing equations for $u_{k}(x)$ are

$$
\begin{gathered}
L\left(u_{k}(x)\right)-L\left(u_{k-1}(x)\right) \\
=C_{k} N_{0}\left(u_{0}(x)\right) \\
+\sum_{i=1}^{k-1} C_{i}\left[L\left(u_{k-i}(x)\right)+N_{k-i}\right. \\
\left.\times\left(u_{0}(x), u_{1}(x), \ldots, u_{k-1}(x)\right)\right], \\
B\left(u_{k}, \frac{\mathrm{d} u_{k}}{\mathrm{~d} x}\right)=0,
\end{gathered}
$$

where $k=2,3, \ldots$ and $N_{m}\left(u_{0}(x), u_{1}(x), \ldots, u_{m}(x)\right)$ is the coefficient of $p^{m}$ in the expansion of $N(v(x, p))$ about the embedding parameter $p$ :

$$
\begin{aligned}
N\left(v\left(x, p, C_{i}\right)\right) & \\
= & N_{0}\left(u_{0}(x)\right) \\
& +\sum_{m=1}^{\infty} N_{m}\left(u_{0}(x), u_{1}(x), \ldots, u_{m}(x)\right) p^{m} .
\end{aligned}
$$

It has been observed that the convergence of the series (7) depends upon the auxiliary constants $C_{1}, C_{2}, C_{3}, \ldots$. If it is convergent at $p=1$, one has

$$
v\left(x, C_{i}\right)=u_{0}(x)+\sum_{k=1}^{\infty} u_{k}\left(x, C_{1}, C_{2}, \ldots, C_{k}\right) .
$$

The result of the $m$ th-order approximation is given

$$
\tilde{u}\left(x, C_{1}, C_{2}, C_{3}, \ldots, C_{m}\right)=u_{0}(x)+\sum_{i=1}^{m} u_{i}\left(x, C_{1}, C_{2}, \ldots, C_{i}\right) .
$$

Substituting (12) into (3) yields the following residual:

$$
\begin{aligned}
R\left(x, C_{1}, C_{2}, C_{3}, \ldots, C_{m}\right) & \\
= & L\left(\widetilde{u}\left(x, C_{1}, C_{2}, C_{3}, \ldots, C_{m}\right)\right)+g(x) \\
& +N\left(\widetilde{u}\left(x, C_{1}, C_{2}, C_{3}, \ldots, C_{m}\right)\right) .
\end{aligned}
$$

If $R=0$, then $\tilde{u}$ will be the exact solution. Generally such a case will not arise for nonlinear problems, but we can minimize the functional

$$
J\left(C_{1}, C_{2}, C_{3}, \ldots, C_{m}\right)=\int_{a}^{b} R^{2}\left(x, C_{1}, C_{2}, C_{3}, \ldots, C_{m}\right) d x
$$

where $a$ and $b$ are the endpoints of the given problem. The unknown constants $C_{i}(i=1,2,3, \ldots, m)$ can be identified from the conditions

$$
\frac{\partial J}{\partial C_{1}}=\frac{\partial J}{\partial C_{2}}=\cdots=\frac{\partial J}{\partial C_{m}}=0 .
$$

With these constants known, the approximate solution (of order $m$ ) is well determined. 


\section{Numerical Examples}

To illustrate the effectiveness of the OHAM we will consider three examples of singular two-point BVPs.

Example 1. Consider the following singular two-point BVP $[2,31]:$

$$
u^{\prime \prime}(x)+\frac{1}{x} u^{\prime}(x)+u(x)=g(x), \quad 0 \leq x \leq 1,
$$

subject to the boundary conditions

$$
u(0)=0, \quad u(1)=0 ;
$$

the exact solution of this problem in case of

$$
g(x)=4-9 x+x^{2}-x^{3}
$$

is given by

$$
u(x)=x^{2}-x^{3}
$$

According to the OHAM formulation described in the above section, we start with

$$
\begin{gathered}
L[v(x, p)]=x \frac{d^{2} v(x, p)}{d x^{2}}+\frac{1}{x} \frac{d v(x, p)}{d x}, \\
N[v(x, p)]=x \frac{d^{2} v(x, p)}{d x^{2}}+\frac{d v(x, p)}{d x}+x v(x, p)-x g(x) .
\end{gathered}
$$

Now, apply (4) at $p=0$ to give the zeroth-order problem as follows:

$$
u_{0}^{\prime \prime}(x)=0
$$

with conditions

$$
u_{0}(0)=0, \quad u_{0}(1)=0,
$$

it gives us

$$
u_{0}(x)=0 .
$$

Now, apply (8) to give the first-order problem as follows:

$$
\begin{aligned}
u_{1}^{\prime \prime}\left(x, C_{1}\right)= & -4 C_{1}+9 x C_{1}-x^{2} C_{1}+x^{3} C_{1}+c_{1} u_{0}(x) \\
& +\frac{u_{0}^{\prime}(x)}{x}+\frac{C_{1} u_{0}^{\prime}(x)}{x}-\frac{u_{1}^{\prime}(x)}{x}+C_{1}\left(u_{0}\right)^{\prime \prime}(x)
\end{aligned}
$$

subject to the boundary conditions

$$
u_{1}(0)=0, \quad u_{1}(1)=0
$$

and having the solution

$$
u_{1}\left(x, C_{1}\right)=\frac{1}{400}\left(9-400 x^{2}+400 x^{3}-25 x^{4}+16 x^{5}\right) C_{1}
$$

The second-order problem can be defined by (9):

$$
\begin{aligned}
& u_{2}^{\prime \prime}\left(x, C_{1}, C_{2}\right) \\
& \quad=-4 C_{2}+9 x C_{2}-x^{2} C_{2}+x^{3} C_{2}+C_{2} u_{0}(x)
\end{aligned}
$$

$$
\begin{aligned}
& +C_{1} u_{1}(x)+\frac{C_{2} u_{0}^{\prime}(x)}{x}+\frac{u_{1}^{\prime}(x)}{x}+\frac{C_{1} u_{1}^{\prime}(x)}{x} \\
& -\frac{u_{2}^{\prime}(x)}{x}+C_{2} u_{0}^{\prime \prime}(x)+u_{1}^{\prime \prime}(x)+C_{1} u_{1}^{\prime \prime}(x)
\end{aligned}
$$

subject to the boundary problem

$$
u_{2}(0)=0, \quad u_{2}(1)=0
$$

and has the solution

$$
\begin{aligned}
& u_{2}\left(x, C_{1}, C_{2}\right) \\
& =\left(\frac{9}{400}-x^{2}+x^{3}-\frac{x^{4}}{16}+\frac{x^{5}}{25}\right) C_{1} \\
& +\left(\frac{1777}{44100}-\frac{1591 x^{2}}{1600}+x^{3}\right. \\
& \left.\quad-\frac{x^{4}}{8}+\frac{2 x^{5}}{25}-\frac{x^{6}}{576}+\frac{x^{7}}{1225}\right) C_{1}^{2} \\
& +\frac{1}{400}\left(9-400 x^{2}+400 x^{3}-25 x^{4}+16 x^{5}\right) C_{2} .
\end{aligned}
$$

By applying (10), the third-order problem is defined as follows:

$$
\begin{aligned}
u_{3}^{\prime \prime}\left(x, C_{1}, C_{2}, C_{3}\right) & \\
= & -4 C_{3}+9 x C_{3}-x^{2} C_{3}+x^{3} C_{3} \\
& +C_{3} u_{0}(x)+C_{2} u_{1}(x)+C_{1} u_{2}(x)+\frac{C_{3} u_{0}^{\prime}(x)}{x} \\
& +\frac{C_{2} u_{1}^{\prime}(x)}{x}+\frac{u_{2}^{\prime}(x)}{x}+\frac{C_{1} u_{2}^{\prime}(x)}{x}-\frac{u_{3}^{\prime}(x)}{x} \\
& +C_{3} u_{0}^{\prime \prime}(x)+C_{2} u_{1}^{\prime \prime}(x)+u_{2}^{\prime \prime}(x)+C_{1} u_{2}^{\prime \prime}(x)
\end{aligned}
$$

subject to the boundary problem

$$
u_{3}(0)=0, \quad u_{3}(1)=0
$$

and has the solution

$$
\begin{aligned}
u_{3}\left(x, C_{1}, C_{2}, C_{3}\right) & \\
= & \frac{9 C_{1}}{400}-x^{2} C_{1}+x^{3} C_{1}-\frac{x^{4} C_{1}}{16}+\frac{x^{5} C_{1}}{25} \\
& +\frac{1777 C_{1}^{2}}{22050}-\frac{1591}{800} x^{2} C_{1}^{2}+2 x^{3} C_{1}^{2}-\frac{1}{4} x^{4} C_{1}^{2} \\
& +\frac{4}{25} x^{5} C_{1}^{2}-\frac{1}{288} x^{6} C_{1}^{2}+\frac{2 x^{7} C_{1}^{2}}{1225}+\frac{22038893 C_{1}^{3}}{406425600} \\
& -\frac{694523 x^{2} C_{1}^{3}}{705600}+x^{3} C_{1}^{3}-\frac{4791 x^{4} C_{1}^{3}}{25600}+\frac{3}{25} x^{5} C_{1}^{3} \\
& -\frac{1}{192} x^{6} C_{1}^{3}+\frac{3 x^{7} C_{1}^{3}}{1225}-\frac{x^{8} C_{1}^{3}}{36864}+\frac{x^{9} C_{1}^{3}}{99225}+\frac{9 C_{2}}{400}
\end{aligned}
$$


TABLE 1: Comparison of the exact solution and the OHAM solution for Example 1.

\begin{tabular}{lcccc}
\hline$x$ & Exact solution & OHAM solution $(3$ terms $)$ & CGA solution [7] & Absolute error \\
\hline 0.1 & 0.0090 & 0.0089895718978 & 0.0089999999973 & $1.04281000 \times 10^{-5}$ \\
0.2 & 0.0320 & 0.0319909691543 & 0.0319999999954 & $9.03084567 \times 10^{-6}$ \\
0.3 & 0.0630 & 0.0629929391328 & 0.0629999999949 & $7.06086713 \times 10^{-6}$ \\
0.4 & 0.0960 & 0.0959950247523 & 0.0959999999950 & $4.97524765 \times 10^{-6}$ \\
0.5 & 0.1250 & 0.1249967655986 & 0.1249999999952 & $3.23440137 \times 10^{-6}$ \\
0.6 & 0.1440 & 0.1439978797237 & 0.1439999999957 & $2.12027629 \times 10^{-6}$ \\
0.7 & 0.1470 & 0.1469984038747 & 0.1469999999965 & $1.59612524 \times 10^{-6}$ \\
0.8 & 0.1280 & 0.1279987010935 & 0.1279999999976 & $1.29890642 \times 10^{-6}$ \\
0.9 & 0.0810 & 0.0809992354577 & 0.0809999999988 & $7.64542249 \times 10^{-7}$ \\
\hline
\end{tabular}

$$
\begin{aligned}
& -x^{2} C_{2}+x^{3} C_{2}-\frac{x^{4} C_{2}}{16}+\frac{x^{5} C_{2}}{25}+\frac{1777 C_{1} C_{2}}{22050} \\
& -\frac{1591}{800} x^{2} C_{1} C_{2}+2 x^{3} C_{1} C_{2}-\frac{1}{4} x^{4} C_{1} C_{2} \\
& +\frac{4}{25} x^{5} C_{1} C_{2}-\frac{1}{288} x^{6} C_{1} C_{2}+\frac{2 x^{7} C_{1} C_{2}}{1225}+\frac{9 C_{3}}{400} \\
& -x^{2} C_{3}+x^{3} C_{3}-\frac{x^{4} C_{3}}{16}+\frac{x^{5} C_{3}}{25} .
\end{aligned}
$$

Using (24), (27), (30), and (33), the third-order approximate solution by OHAM for $p=1$ is as follows:

$$
\begin{aligned}
\tilde{u}\left(x, C_{1}, C_{2}, C_{3}\right)= & u_{0}(x)+u_{1}\left(x, C_{1}\right) \\
& +u_{2}\left(x, C_{1}, C_{2}\right)+u_{3}\left(x, C_{1}, C_{2}, C_{3}\right) .
\end{aligned}
$$

Following the procedure described in Section 2 on the domain between $a=0$ and $b=1$, using the residual error,

$$
\begin{aligned}
R= & x \tilde{u}^{\prime \prime}\left(x, C_{1}, C_{2}, C_{3}\right)+\tilde{u}^{\prime}\left(x, C_{1}, C_{2}, C_{3}\right) \\
& +x \tilde{u}\left(x, C_{1}, C_{2}, C_{3}\right)-x\left(4-9 x+x^{2}-x^{3}\right) .
\end{aligned}
$$

The less square method can be applied as

$$
\begin{gathered}
J\left(C_{1}, C_{2}, C_{3}\right)=\int_{0}^{1} R^{2} d x, \\
\frac{d J}{d C_{1}}=\frac{d J}{d C_{2}}=\frac{d J}{d C_{3}} .
\end{gathered}
$$

Thus, the following optimal values of $C_{i}$ 's are obtained:

$$
\begin{gathered}
C_{1}=-1.076627460, \quad C_{2}=-0.005293863, \\
C_{3}=-0.000381048 .
\end{gathered}
$$

By considering these values our approximate solution becomes

$$
\begin{aligned}
\tilde{u}\left(x, C_{1}, C_{2}, C_{3}\right) \\
=-0.0000109358+0 \cdot x+1.00005 x^{2}-1.00002 x^{3} \\
\quad+7.25718 \times 10^{-6} x^{4}-0.000285432 x^{5}
\end{aligned}
$$

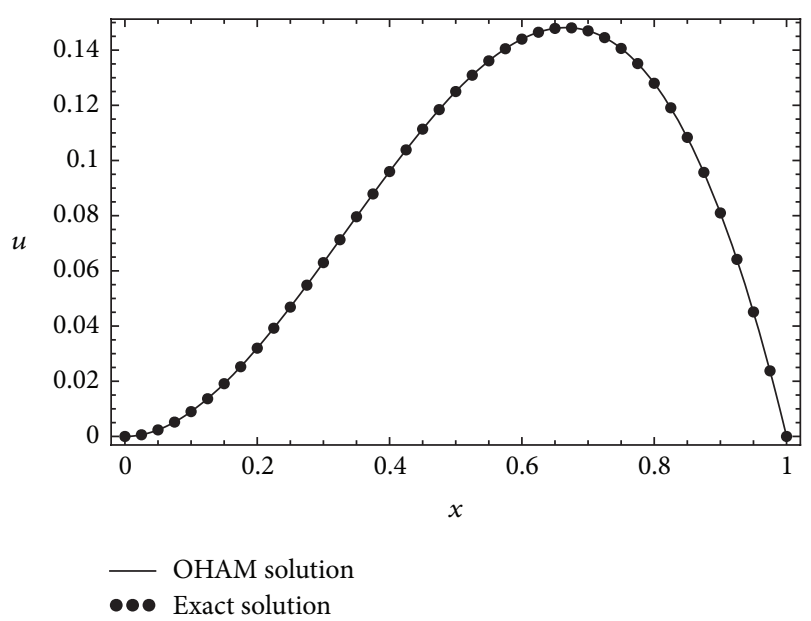

Figure 1: Exact and approximate solution using OHAM for Example 1.

$$
\begin{aligned}
& +0.000442819 x^{6}-0.000208215 x^{7} \\
& +0.0000338527 x^{8}-0.0000125769 x^{9}
\end{aligned}
$$

It is clear that the given solution is very close to the exact one since the other terms' approach zero which leads to that the solution is converge. Moreover, Table 1 exhibits the approximate solution obtained by using the OHAM and CGA [7]. It is clear that the obtained results in a our method are in very good agreement with the exact solution, which proves the reliability of the method. In Figure 1 we plot the approximate solution and the exact solution.

Example 2. Let us consider the singular two-point BVP $[2,3]$ :

$$
\begin{gathered}
u^{\prime \prime}(x)+\frac{1}{x} u^{\prime}(x)+u(x)=g(x), \quad 0 \leq x \leq 1, \\
u^{\prime}(0)=0, \quad u(1)=\frac{17}{16} .
\end{gathered}
$$

The exact solution of this problem in the case of

$$
g(x)=\frac{5}{4}+\frac{x^{2}}{16}
$$


TABLE 2: Comparison of the exact solution and the OHAM solution for Example 2.

\begin{tabular}{lcccc}
\hline$x$ & Exact solution & OHAM solution (3 terms) & VIM solution [3] & Absolute error \\
\hline 0.1 & 1.0006 & 1.0006255449104 & 0.8665109375000 & $5.44910481 \times 10^{-7}$ \\
0.2 & 1.0025 & 1.0025004672985 & 0.8723000000000 & $4.67298560 \times 10^{-7}$ \\
0.3 & 1.0056 & 1.0056253598830 & 0.8819692708333 & $3.59883028 \times 10^{-7}$ \\
0.4 & 1.0100 & 1.0100002486730 & 0.895550000000 & $2.48673017 \times 10^{-7}$ \\
0.5 & 1.0156 & 1.0156251578232 & 0.9130859375000 & $1.57823275 \times 10^{-7}$ \\
0.6 & 1.0225 & 1.0225001009617 & 0.9346333333333 & $1.00961799 \times 10^{-7}$ \\
0.7 & 1.0306 & 1.0306250751620 & 0.9602609375000 & $7.51620191 \times 10^{-8}$ \\
0.8 & 1.0400 & 1.0400000614013 & 0.9900500000000 & $6.14013284 \times 10^{-8}$ \\
0.9 & 1.0506 & 1.0506250362014 & 1.0240942708333 & $3.62014673 \times 10^{-8}$ \\
\hline
\end{tabular}

is given by

$$
u(x)=1+\frac{x^{2}}{16}
$$

According to the OHAM formulation described in the previous section, we start with

$$
\begin{gathered}
L[v(x, p)]=x \frac{d^{2} v(x, p)}{d x^{2}}+\frac{1}{x} \frac{d v(x, p)}{d x} \\
N[v(x, p)]=x \frac{d^{2} v(x, p)}{d x^{2}}+\frac{d v(x, p)}{d x}+x v(x, p)-x g(x) .
\end{gathered}
$$

Applying OHAM, we have the following zeroth-, first-, second-, and the third-order problem solutions:

$$
\begin{gathered}
u_{0}(x)=\frac{17}{16}, \\
u_{1}\left(x, C_{1}\right)=\frac{13 C_{1}}{256}-\frac{3 x^{2} C_{1}^{2}}{64}-\frac{x^{4} C_{1}}{256}, \\
u_{2}\left(x, C_{1}, C_{2}\right)=\frac{13 C_{1}}{256}-\frac{3 x^{2} C_{1}}{64}-\frac{x^{4} C_{1}}{256} \\
+\frac{379 C_{1}^{2}}{9216}-\frac{35 x^{2} C_{1}^{2}}{1024}-\frac{7 x^{4} C_{1}^{2}}{1024} \\
-\frac{x^{6} C_{1}^{2}}{9216}+\frac{13 C_{2}}{256}-\frac{3 x^{2} C_{2}}{64}, \\
u_{3}\left(x, C_{1}, C_{2}, C_{3}\right) \\
=\frac{13 C_{1}}{256}-\frac{3 x^{2} C_{1}}{64}-\frac{x^{4} C_{1}}{256}+\frac{379 C_{1}^{2}}{4608}-\frac{35 x^{2} C_{1}^{2}}{512} \\
-\frac{7 x^{4} C_{1}^{2}}{512}-\frac{x^{6} C_{1}^{2}}{4608}+\frac{19565 C_{1}^{3}}{589824}-\frac{881 x^{2} C_{1}^{3}}{589824} \\
-\frac{147 x^{4} C_{1}^{3}}{16384}-\frac{11 x^{6} C_{1}^{3}}{36864}-\frac{x^{8} C_{1}^{3}}{589824}-\frac{13 C_{2}}{256}
\end{gathered}
$$

$$
\begin{aligned}
& -\frac{3 x^{2} C_{2}}{64}-\frac{x^{4} C_{2}}{256}+\frac{379 C_{1} C_{2}}{4608}-\frac{35 x^{2} C_{1} C_{2}}{512} \\
& -\frac{7 x^{4} C_{1} C_{2}}{512}-\frac{x^{6} C_{1} C_{2}}{4608}+\frac{13 C_{3}}{256}-\frac{3 x^{2} C_{3}}{64}-\frac{x^{4} C_{3}}{256} .
\end{aligned}
$$

Using (43) we obtain the following third-order approximate solution by OHAM:

$$
\begin{aligned}
\tilde{u}\left(x, C_{1}, C_{2}, C_{3}\right)= & u_{0}(x)+u_{1}\left(x, C_{1}\right)+u_{2}\left(x, C_{1}, C_{2}\right) \\
& +u_{3}\left(x, C_{1}, C_{2}, C_{3}\right) .
\end{aligned}
$$

Following the procedure described in Section 2 on the domain between $a=0$ and $b=1$, using the residual

$$
\begin{aligned}
R= & x \tilde{u}^{\prime \prime}\left(x, C_{1}, C_{2}, C_{3}\right)+\tilde{u}^{\prime}\left(x, C_{1}, C_{2}, C_{3}\right) \\
& +x \tilde{u}\left(x, C_{1}, C_{2}, C_{3}\right)-x\left(\frac{5}{4}+\frac{x^{2}}{16}\right) .
\end{aligned}
$$

The following optimal values of $C_{i}$ 's are obtained:

$$
\begin{gathered}
C_{1}=-1.0769, \quad C_{2}=-0.00539311, \\
C_{3}=-0.000394546 .
\end{gathered}
$$

By considering these values, our approximate solution becomes

$$
\begin{aligned}
\widetilde{u}\left(x, C_{1}, C_{2}, C_{3}\right) & \\
= & 1.0+0.0624971 x^{2}+6.3086 \times 10^{-6} x^{4} \\
& \quad-6.10932 \times 10^{-6} x^{6}+2.11738 \times 10^{-6} x^{8} .
\end{aligned}
$$

Therefore, we have the third-order approximate solution of Example 2.

Table 2 shows a comparison between the OHAM solution and the solutions of VIM [3] both with the exact solution. As it is an evident from the compared results, it was found that OHAM gives better results. In Figure 2, both the approximate solution by using OHAM and the exact solution have been plotted. 


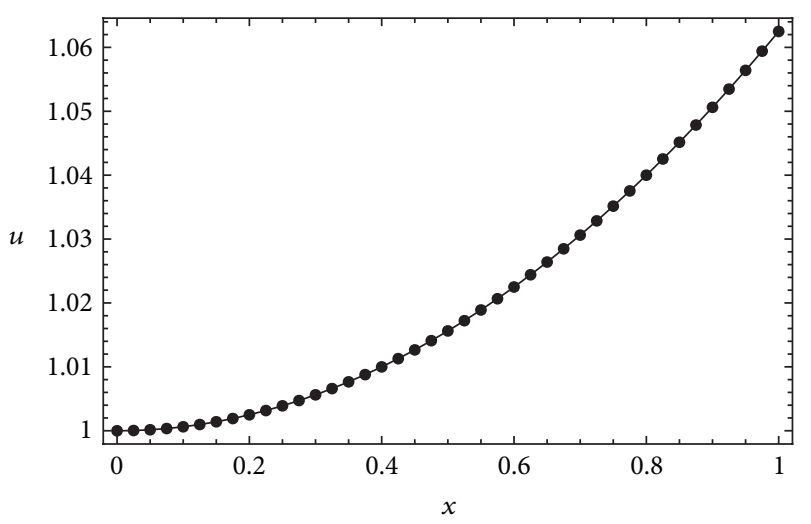

OHAM solution

$\bullet$ Exact solution

FIgURE 2: Exact and approximate solution using OHAM for Example 2.

Example 3. Consider the singular two-point BVP $[2,8]$

$$
\begin{gathered}
\left(1-\frac{x}{2}\right) u^{\prime \prime}(x)+\frac{3}{2}\left(\frac{1}{x}-1\right) u^{\prime}(x)+\left(\frac{x}{2}-1\right) u(x) \\
=g(x), \quad 0 \leq x \leq 1, \\
u^{\prime}(0)=0, \quad u(1)=0 .
\end{gathered}
$$

The exact solution of this problem in the case of

$$
g(x)=5-\frac{29 x}{2}+\frac{13 x^{2}}{2}+\frac{3 x^{3}}{2}-\frac{x^{4}}{2}
$$

is given by

$$
u(x)=x^{2}-x^{3}
$$

According to the OHAM formulation described in the above section, we start with

$$
\begin{gathered}
L[v(x, p)]=\frac{d^{2} v(x, p)}{d x^{2}}+\frac{d v(x, p)}{d x} \\
N[v(x, p)]=\left(x-\frac{1}{2}\right) \frac{d^{2} v(x, p)}{d x^{2}}+\frac{3}{2}(1-x) \frac{d v(x, p)}{d x} \\
+\frac{x^{2}-2 x}{2} v(x, p)-x g(x) .
\end{gathered}
$$

Applying OHAM, we have the following zeroth-, first-, and second-order solutions:

$$
\begin{aligned}
& u_{0}(x)=0 \\
& u_{1}\left(x, C_{1}\right)= \frac{1741 C_{1}}{120}+\frac{23 C_{1}}{e}-\frac{23 C_{1}}{e}-23 x C_{1}+\frac{23 x^{2} C_{1}}{2} \\
&-\frac{14 x^{3} C_{1}}{3}+\frac{19 x^{4} C_{1}}{8}-\frac{4 x^{5} C_{1}}{5}+\frac{x^{6} C_{1}}{12}
\end{aligned}
$$

$$
\begin{aligned}
u_{2}\left(x, C_{1}, C_{2}\right) & =\frac{1741 C_{1}}{120}+\frac{23 C_{1}}{e}-\frac{23 C_{1}}{e^{x}}-23 x C_{1}+\frac{23 x^{2} C_{1}}{2} \\
& -\frac{14 x^{3} C_{1}}{3}+\frac{19 x^{4} C_{1}}{8}-\frac{4 x^{5} C_{1}}{5}+\frac{x^{6} C_{1}}{12}-\frac{4057507 C_{1}^{2}}{6048} \\
& -\frac{46 C_{1}^{2}}{e^{2}}-\frac{11141 C_{1}^{2}}{10 e}+\frac{46 C_{1}^{2}}{e^{(-1-x)}}+\frac{64201 C_{1}^{2}}{60 e^{-x}} \\
& +\frac{64201 x C_{1}^{2}}{60}+\frac{46 x C_{1}^{2}}{e}-\frac{66271 x^{2} C_{1}^{2}}{120}-\frac{23 x^{2} C_{1}^{2}}{e} \\
& +\frac{69 x^{2} C_{1}^{2}}{4 e^{-x}}+\frac{141841 x^{3} C_{1}^{2}}{720}+\frac{23 x^{3} C_{1}^{2}}{6 e}-\frac{2623 x^{4} C_{1}^{2}}{48} \\
& +\frac{41 x^{5} C_{1}^{2}}{3}-\frac{1301 x^{6} C_{1}^{2}}{360}+\frac{1369 x^{7} C_{1}^{2}}{1680}-\frac{49 x^{8} C_{1}^{2}}{480} \\
& +\frac{x^{9} C_{1}^{2}}{216}+\frac{1741 C_{2}}{120}+\frac{23 C_{2}}{e}-\frac{23 C_{2}}{e^{x}}-23 x C_{2} \\
& +\frac{23 x^{2} C_{2}}{2}-\frac{14 x^{3} C_{2}}{3}+\frac{19 x^{4} C_{2}}{8}-\frac{4 x^{5} C_{2}}{5}+\frac{x^{6} C_{2}}{12}
\end{aligned}
$$

Using (52) and also by adding the solutions of the third-order problems, we obtain the following third-order approximate solution by OHAM:

$$
\tilde{u}\left(x, C_{1}, C_{2}, C_{3}\right)=u_{0}(x)+u_{1}\left(x, C_{1}\right)+u_{2}\left(x, C_{1}, C_{2}\right)
$$

$$
+u_{3}\left(x, C_{1}, C_{2}, C_{3}\right) \text {. }
$$

Following the procedure described in Section 2 on the domain between $a=0$ and $b=1$, using the residual

$$
\begin{aligned}
R= & \left(x-\frac{x^{2}}{2}\right) \tilde{u}^{\prime \prime}\left(x, C_{1}, C_{2}, C_{3}\right) \\
& +\frac{3}{2}(1-x) \tilde{u}^{\prime}\left(x, C_{1}, C_{2}, C_{3}\right) \\
& +\left(\frac{x^{2}}{2}-x\right) \tilde{u}\left(x, C_{1}, C_{2}, C_{3}\right) \\
& -x\left(5-\frac{29 x}{2}+\frac{13 x^{2}}{2}+\frac{3 x^{3}}{2}-\frac{x^{4}}{2}\right) .
\end{aligned}
$$

The following optimal values of $C_{i}$ 's are obtained:

$$
\begin{gathered}
C_{1}=-2.5182, \quad C_{2}=-0.0304705, \\
C_{3}=-0.00712009 .
\end{gathered}
$$


TABLE 3: Comparison of the exact solution and the OHAM solution for Example 3.

\begin{tabular}{lcccc}
\hline$x$ & Exact solution & OHAM solution (3 terms) & OHAM error & He's HPM error [8] \\
\hline 0.1 & 0.0090 & 0.0099841073222 & $9.841 \times 10^{-4}$ & $8.936 \times 10^{-4}$ \\
0.2 & 0.0320 & 0.0291990486850 & $2.801 \times 10^{-3}$ & $8.631 \times 10^{-4}$ \\
0.3 & 0.0630 & 0.0600046093219 & $2.995 \times 10^{-3}$ & $8.120 \times 10^{-4}$ \\
0.4 & 0.0960 & 0.0941688334742 & $1.831 \times 10^{-3}$ & $7.408 \times 10^{-4}$ \\
0.5 & 0.1250 & 0.1241809960356 & $8.190 \times 10^{-4}$ & $6.507 \times 10^{-4}$ \\
0.6 & 0.1440 & 0.1437292946566 & $2.707 \times 10^{-4}$ & $5.435 \times 10^{-4}$ \\
0.7 & 0.1470 & 0.14693478562367 & $6.521 \times 10^{-5}$ & $4.215 \times 10^{-4}$ \\
0.8 & 0.1280 & 0.1279073412152 & $9.266 \times 10^{-5}$ & $2.878 \times 10^{-4}$ \\
0.9 & 0.0810 & 0.0808082770963 & $1.917 \times 10^{-4}$ & $1.467 \times 10^{-9}$ \\
\hline
\end{tabular}

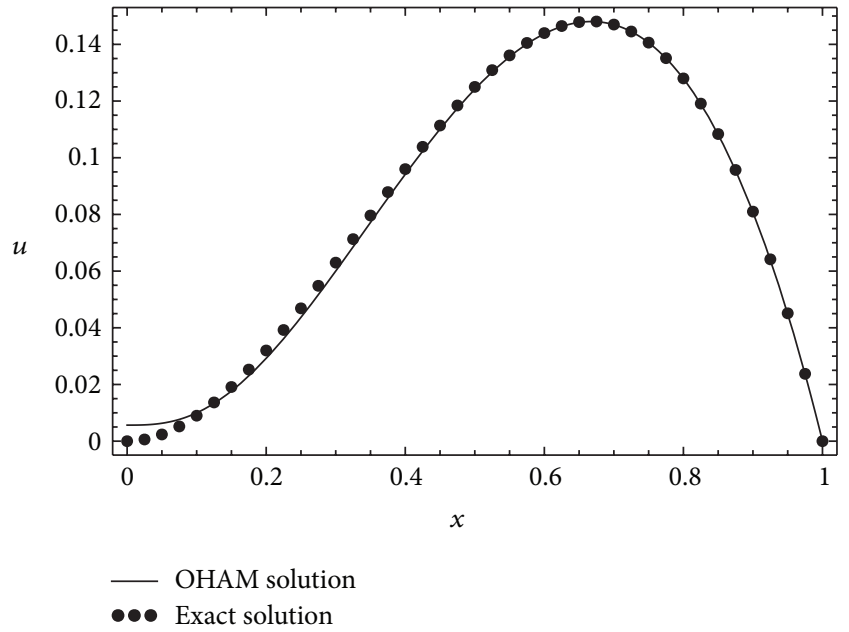

Figure 3: Exact and approximate solution using OHAM for Example 3.

The approximate solution now becomes

$$
\begin{aligned}
& \widetilde{u}\left(x, C_{1}, C_{2}, C_{3}\right) \\
&=-1.40959 \times 10^{6}+2.81716 \times 10^{7} e^{-3-x} \\
&+51363.2 e^{-2-x}+57.9185 e^{-x}+1.40766 \times 10^{6} x \\
&+38729.3 e^{-3-x} x-717179 \cdot x^{2}+285281 \cdot e^{-3-x} x^{2} \\
&+808.272 e^{-2-x} x^{2}+248195 \cdot x^{3}+1844.25 e^{-3-x} x^{3} \\
&-65742 \cdot x^{4}+4841.17 e^{-3-x} x^{4}+14295.2 x^{5} \\
&-2702.04 x^{6}+477.666 x^{7}-84.9559 x^{8}+14.2263 x^{9} \\
&-1.7433 x^{10}+0.117783 x^{11}-0.00308038 x^{12} .
\end{aligned}
$$

Table 3 exhibits the approximate solution obtained by using the OHAM and He's HPM [8]. It can be seen that the solution obtained by our procedure is nearly identical with that given by the exact solution, which proves the reliability of the method. In Figure 3 we compare the exact solution and the approximate solution obtained by OHAM.

\section{Conclusions}

In this work, OHAM has been applied successfully to solve singular two-point BVPs. The results which are obtained by using OHAM are in a good agreement with the exact solution as well as the results which are already presented in the literature like CGA, VIM, and HPM. This shows that the method is efficient and reliable for the solution of singular two-point boundary value problems.

\section{Acknowledgment}

The authors thank the anonymous referees for their comments which improved the paper.

\section{References}

[1] S. Chandrasekhar, Hydrodynamic and Hydromagnetic Stability, Dover, New York, NY, USA, 1981.

[2] A. S. Bataineh, M. S. M. Noorani, and I. Hashim, "Approximate solutions of singular two-point BVPs by modified homotopy analysis method," Physics Letters A, vol. 372, no. 22, pp. $4062-$ 4066, 2008.

[3] J. Lu, "Variational iteration method for solving two-point boundary value problems," Journal of Computational and Applied Mathematics, vol. 207, no. 1, pp. 92-95, 2007.

[4] A. S. V. R. Kanth and Y. N. Reddy, "Cubic spline for a class of singular two-point boundary value problems," Applied Mathematics and Computation, vol. 170, no. 2, pp. 733-740, 2005.

[5] A. S. V. R. Kanth and K. Aruna, "Solution of singular two-point boundary value problems using differential transformation method," Physics Letters A, vol. 372, no. 26, pp. 4671-4673, 2008.

[6] A. Ebaid and M. D. Aljoufi, "Exact solutions for a class of singular two-point boundary value problems using Adomian decomposition method," Applied Mathematical Sciences, vol. 6, no. 121-124, pp. 6097-6108, 2012.

[7] O. A. Arqub, Z. Abo-Hammour, S. Momani, and N. Shawagfeh, "Solving singular two-point boundary value problems using continuous genetic algorithm," Abstract and Applied Analysis, vol. 2012, Article ID 205391, 25 pages, 2012.

[8] K. Al-Khaled, "Theory and computation in singular boundary value problems," Chaos, Solitons and Fractals, vol. 33, no. 2, pp. 678-684, 2007.

[9] M. Jalaal, D. D. Ganji, and G. Ahmadi, "Analytical investigation on acceleration motion of a vertically falling spherical particle 
in incompressible Newtonian media," Advanced Powder Technology, vol. 21, no. 3, pp. 298-304, 2010.

[10] M. Jalaal and D. D. Ganji, "An analytical study on motion of a sphere rolling down an inclined plane submerged in a Newtonian fluid," Powder Technology, vol. 198, no. 1, pp. 82-92, 2010.

[11] M. Jalaal and D. D. Ganji, "On unsteady rolling motion of spheres in inclined tubes filled with incompressible Newtonian fluids," Advanced Powder Technology, vol. 22, no. 1, pp. 58-67, 2011.

[12] M. Jalaal, M. G. Nejad, P. Jalili et al., "Homotopy perturbation method for motion of a spherical solid particle in plane couette fluid flow," Computers and Mathematics with Applications, vol. 61, no. 8, pp. 2267-2270, 2011.

[13] M. Esmaeilpour and D. D. Ganji, "Application of He's homotopy perturbation method to boundary layer flow and convection heat transfer over a flat plate," Physics Letters A, vol. 372, no. 1, pp. 33-38, 2007.

[14] S. J. Liao, The proposed homotopy analysis techniques for the solution of nonlinear problems [Ph.D. thesis], Shanghai Jiao Tong University, 1992.

[15] S. J. Liao, Beyond Perturbation: Introduction to the Homotopy Analysis Method, vol. 2 of CRC Series: Modern Mechanics and Mathematics, Chapman \& Hall/CRC, Boca Raton, Fla, USA, 2004.

[16] S. J. Liao, "An explicit, totally analytic approximate solution for Blasius' viscous flow problems," International Journal of NonLinear Mechanics, vol. 34, no. 4, pp. 759-778, 1999.

[17] S. J. Liao, "On the homotopy analysis method for nonlinear problems," Applied Mathematics and Computation, vol. 147, no. 2, pp. 499-513, 2004.

[18] S. J. Liao, "An approximate solution technique not depending on small parameters: a special example," International Journal of Non-Linear Mechanics, vol. 30, no. 3, pp. 371-380, 1995.

[19] S. J. Liao, "A kind of approximate solution technique which does not depend upon small parameters-II: an application in fluid mechanics," International Journal of Non-Linear Mechanics, vol. 32, no. 5, pp. 815-822, 1997.

[20] S. J. Liao, "Comparison between the homotopy analysis method and homotopy perturbation method," Applied Mathematics and Computation, vol. 169, no. 2, pp. 1186-1194, 2005.

[21] S. J. Liao, "A new branch of solutions of boundary-layer flows over an impermeable stretched plate," International Journal of Heat and Mass Transfer, vol. 48, no. 12, pp. 2529-2539, 2005.

[22] T. Hayat and M. Khan, "Homotopy solutions for a generalized second-grade fluid past a porous plate," Nonlinear Dynamics, vol. 42, no. 4, pp. 395-405, 2005.

[23] M. Ayub, A. Rasheed, and T. Hayat, "Exact flow of a third grade fluid past a porous plate using homotopy analysis method," International Journal of Engineering Science, vol. 41, no. 18, pp. 2091-2103, 2003.

[24] I. T. Abu-Zaid and M. A. El-Gebeily, "A finite difference method for approximating the solution of a certain class of singular twopoint boundary value problems," Arab Journal of Mathematical Sciences, vol. 1, no. 1, pp. 25-39, 1995.

[25] A. M. Siddiqui, M. Ahmed, and Q. K. Ghori, "Couette and poiseuille flows for non-newtonian fluids," International Journal of Nonlinear Sciences and Numerical Simulation, vol. 7, no. 1, pp. 15-26, 2006.

[26] N. Herisanu, V. Marinca, T. Dordea, and G. Madescu, "A new analytical approach to nonlinear vibration of an electric machine," Proceedings of Romanian Academy A, vol. 9, no. 3, 2008.

[27] V. Marinca, N. Herisanu, C. Bota, and B. Marinca, "An optimal homotopy asymptotic method applied to the steady flow of a fourth-grade fluid past a porous plate," Applied Mathematics Letters, vol. 22, no. 2, pp. 245-251, 2009.

[28] V. Marinca, N. Herisanu, and I. Nemes, "Optimal homotopy asymptotic method with application to thin film flow," Central European Journal of Physics, vol. 6, no. 3, pp. 648-653, 2008.

[29] V. Marinca and N. Herisanu, "Application of optimal homotopy asymptotic method for solving nonlinear equations arising in heat transfer," International Communications in Heat and Mass Transfer, vol. 35, no. 6, pp. 710-715, 2008.

[30] J. Ali, S. Islam, S. Islam, and G. Zaman, "The solution of multipoint boundary value problems by the optimal homotopy asymptotic method," Computers \& Mathematics with Applications, vol. 59, no. 6, pp. 2000-2006, 2010.

[31] M. Cui and F. Geng, "Solving singular two-point boundary value problem in reproducing kernel space," Journal of Computational and Applied Mathematics, vol. 205, no. 1, pp. 6-15, 2007. 


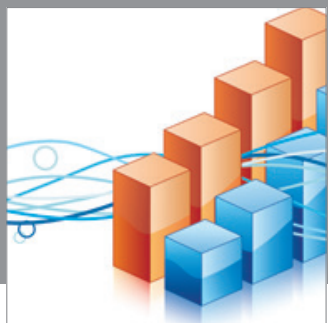

Advances in

Operations Research

mansans

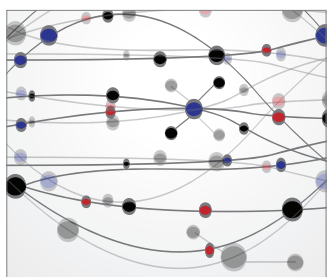

The Scientific World Journal
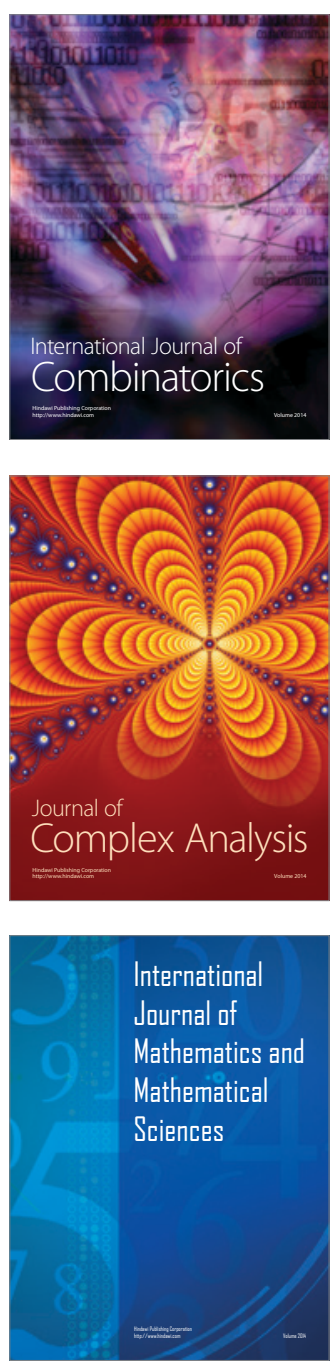
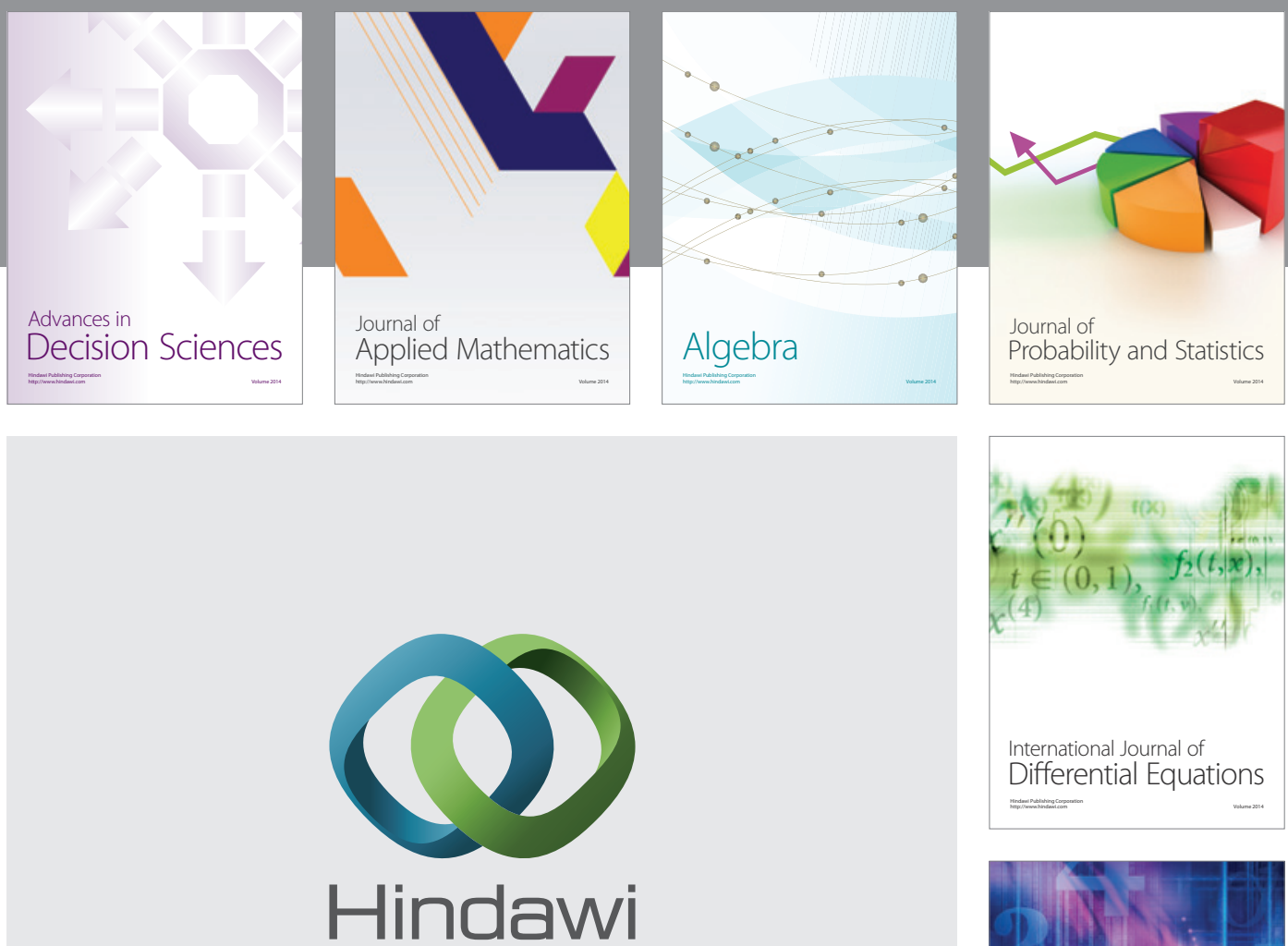

Submit your manuscripts at http://www.hindawi.com
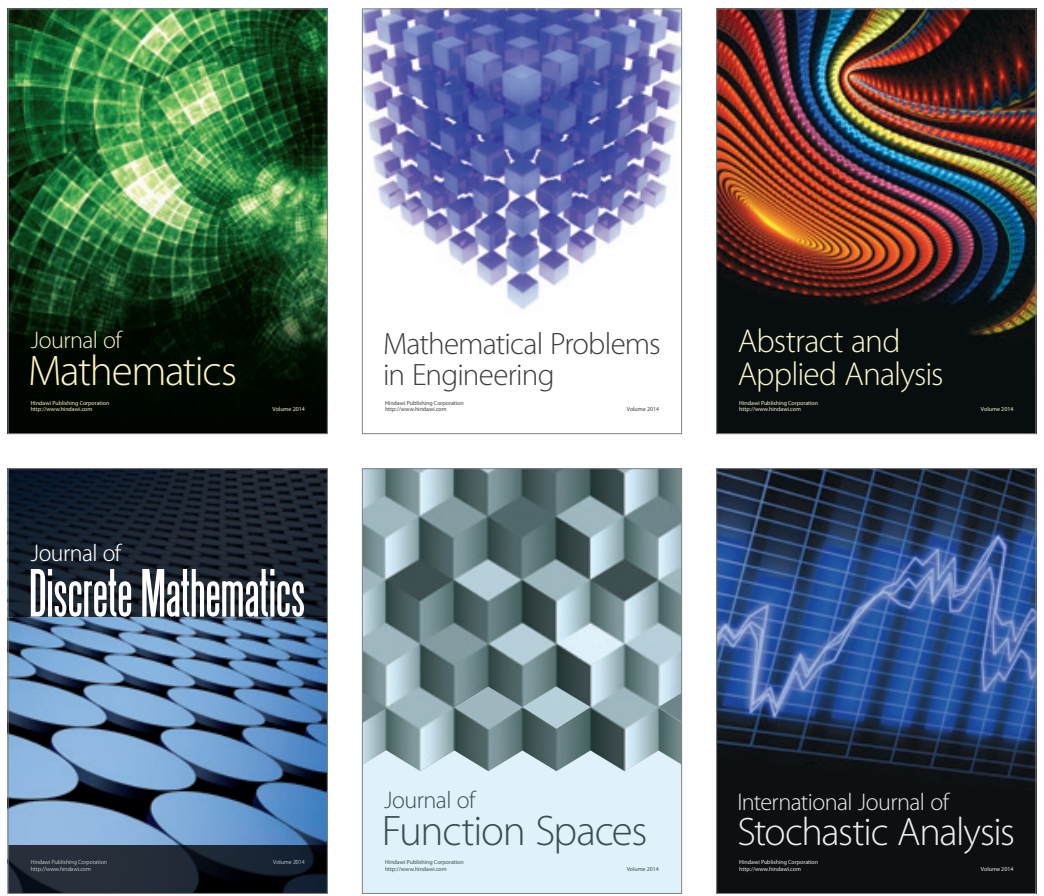

Journal of

Function Spaces

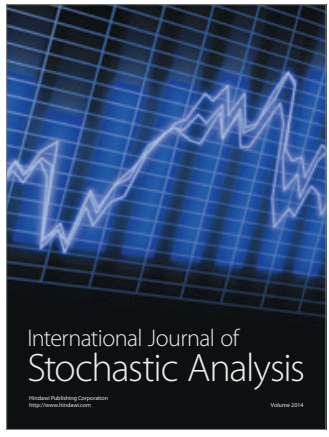

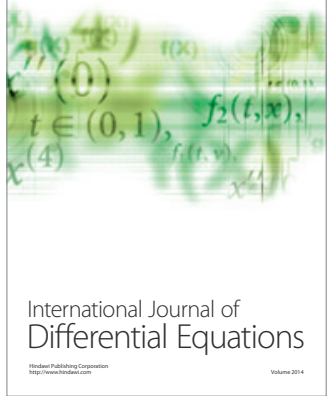
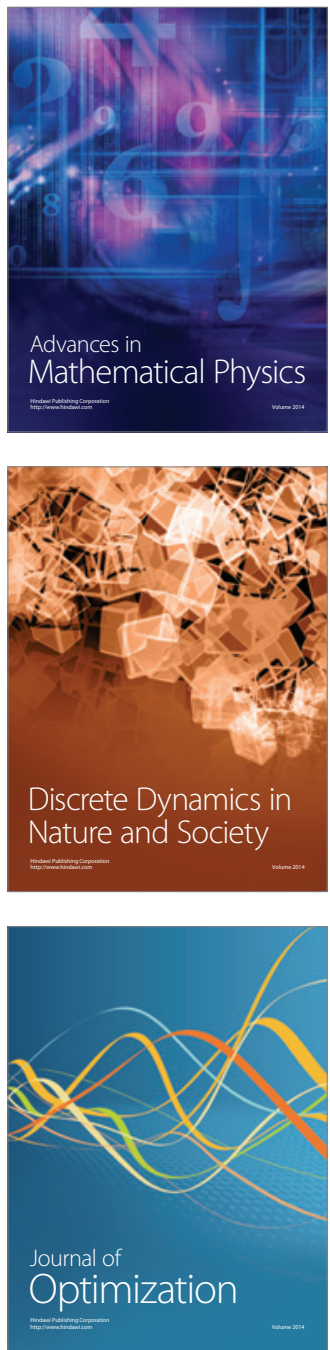